\title{
Intrinsic char reactivity of plastic waste (PET) during $\mathrm{CO}_{2}$ gasification
}

\author{
M.V. Gil, J. Fermoso, C. Pevida, J.J. Pis, F. Rubiera ${ }^{*}$ \\ Instituto Nacional del Carbón, CSIC, Apartado 73, 33080 Oviedo, Spain
}

\begin{abstract}
Char reactivity has a strong influence on the gasification process, since char gasification is the slowest step in the process. A sample of waste PET was devolatilised in a vertical quartz reactor and the resulting char was partially gasified under a $\mathrm{CO}_{2}$ atmosphere at $925^{\circ} \mathrm{C}$ in order to obtain samples with different degrees of conversion. The reactivity of the char in $\mathrm{CO}_{2}$ was determined by isothermal thermogravimetric analysis at different temperatures in a kinetically controlled regime and its reactive behaviour was evaluated by means of the random pore model (RPM). The texture of the char was characterised by means of $\mathrm{N}_{2}$ and $\mathrm{CO}_{2}$ adsorption isotherms. The results did not reveal any variation in char reactivity during conversion, whereas the micropore surface area was affected during the gasification process. It was found that the intrinsic reaction rate of the char can be satisfactorily calculated by normalizing the reaction rate by the narrow micropore surface area calculated from the $\mathrm{CO}_{2}$ adsorption isotherms. It can be concluded therefore that the surface area available for the gasification process is the area corresponding to the narrow microporosity.
\end{abstract}

Keywords: PET; $\mathrm{CO}_{2}$ gasification; intrinsic char reactivity; narrow micropores

\footnotetext{
* Corresponding author. Tel.: +34 985118 975; Fax: +34 985297662

E-mail address: frubiera@incar.csic.es (F. Rubiera)
} 


\section{Introduction}

The amount of residues generated is projected to grow in the foreseeable future. Some materials in waste, such as plastics, metals or ceramics, are not biodegradable and their durability exacerbates the problem of landfill waste sites. It is therefore necessary to find an alternative means of disposal, such as energy recovery from waste, which is more environmentally acceptable [1].

The European Union represents $25 \%$ of the global plastics production, with approximately 60 million tonnes per year. Five types of plastic account for around $75 \%$ of all plastics demand in Europe: polyethylene (PE), polypropylene (PP), polyvinylchloride (PVC), polystyrene (PS) and polyethylene terephthalate (PET). PET is one of the most frequently used raw materials for the manufacture of soft drink bottles. European post-sorting PET collection reached 1.26 million tonnes in 2008 [2]. The European Union Directive 2008/98/EC on waste lays down measures to prevent or reduce the adverse impacts of the generation and management of wastes. It establishes that by 2015 , separate collection shall be set up for plastic and, by 2020 , the preparing for re-use and the recycling of plastic waste shall be increased to a minimum of overall $50 \%$ by weight. The use as a fuel to generate energy is one of the options for waste recovery if the recovery of energy takes place with a high level of energy efficiency.

Waste accumulation of such bottles in landfills can cause serious ecological problems in many developed countries [3]. Gasification or pyrolysis provide a means of producing sustainable energy from the growing amount of plastics in wastes and an alternative way of getting rid of the plastic wastes at the same time [4]. This would help to solve the problem of dumping plastic wastes in landfills [5]. Moreover, plastics have a higher heating value compared to the average heating value of cellulosic material. Plastics have 
the average LHV of $40 \mathrm{MJ} / \mathrm{kg}$, whereas the LHV for cellulosic wastes such as cardboard is $16 \mathrm{MJ} / \mathrm{kg}$ [4]. The gasification of coal and PET blends in a fluidized bed reactor has been studied by Pohořelý et al. [6] and a co-gasification study of biomass and plastic wastes has been carried out by Pinto et al. [7]. Recently, Al-Salem et al. [8] concluded that thermo-chemical methods (pyrolysis, gasification) and energy recovery (coincineration) will soon be developed enough to provide a sustainable solution to the problem of plastic solid waste disposal in the near future.

Gasification involves combusting a fuel with insufficient oxygen to turn all the energy contained in the fuel into chemical energy in the gases produced. The process converts the fuel into a mixture of gases such as carbon monoxide, hydrogen and light hydrocarbons. The gasification process consists of a devolatilization stage of the fuel, when volatile matter such as hydrocarbon gases, tars and phenols are evolved, and a gasification stage of the resultant char, the latter being the controlling stage of the overall process. In gasification systems, there is usually a recirculation of synthesis gas that contains significant quantities of carbon monoxide and hydrogen, which will cause very high temperatures. The volatile matter produced during the devolatilization stage reacts with the oxidant surrounding atmosphere and the volatiles combustion will be therefore much more rapid than the heterogeneous char gasification. The slowest reactions in gasification are these gas-solid reactions with char carbon, such as Boudouard $\left(\mathrm{C}+\mathrm{CO}_{2}\right)$, water gas $\left(\mathrm{C}+\mathrm{H}_{2} \mathrm{O}\right)$ and hydrogenation reactions $\left(\mathrm{C}+\mathrm{H}_{2}\right)$. The water gas shift reaction $\left(\mathrm{CO}+\mathrm{H}_{2} \mathrm{O}\right)$ also can take place and will affect the $\mathrm{CO} / \mathrm{H}_{2}$ ratio in the syngas produced. A good knowledge of char reactivity and its variation during gasification is essential for designing gasification reactors [9]. 
To this end, thermogravimetric analysis is a useful, simple and fast tool for studying the thermal behaviour, reactivity and kinetics parameters of carbonaceous materials [9-13]. By means of thermogravimetry, different models can be applied in order to calculate the parameters of reaction rates. The random pore model (RPM) proposed by Bhatia and Perlmutter [14] has been widely applied to the experimental data obtained from gasification of carbonaceous materials [15-18].

What is more, to fully understand the gasification process, it is necessary to study the pore structure of carbon. Most pore structure models assume that gasification occurs on the surface of the micropores, which make up most of the surface area of char. In the absence of diffusional effects, the intrinsic reactivity of chars can be obtained by dividing the reaction rate by the surface area [19]. However, there is controversy about which is the most suitable surface area to determine intrinsic reactivity [20].

The methods most frequently used to evaluate char microporosity are based on the physical adsorption of gases [21], $\mathrm{N}_{2}$ and $\mathrm{CO}_{2}$ being the adsorbates most widely employed to characterise char texture. $\mathrm{N}_{2}$ adsorption isotherms are usually performed at $-196^{\circ} \mathrm{C}$ and, in these conditions, the results obtained are associated with larger microporosity [22]. $\mathrm{CO}_{2}$ adsorption is usually conducted at $0{ }^{\circ} \mathrm{C}$ and in these conditions this adsorbate is able to penetrate the smaller micropores due to its greater diffusivity compared to $\mathrm{N}_{2}$ [23]. According to Lozano-Castelló et al. [24], $\mathrm{CO}_{2}$ adsorption isotherms should be used as a complement to $\mathrm{N}_{2}$ adsorption when assessing narrow microporosity (pore width $<0.7 \mathrm{~nm}$ ). In contrast, the apparent surface area is usually determined by applying the Brunauer-Emmett-Teller (BET) method to the $\mathrm{N}_{2}$ adsorption isotherms. However, microporosity can also be analysed from the DubininRadushkevich (DR) equation and its modifications, such as Dubinin-Asthakov (DA) or 
Dubinin-Stoeckli (DS) methods, which are based on Dubinin's theory of the volume filling of micropores, the density functional theory (DFT) and the Horvath-Kawazoe method.

The surface area that determines intrinsic reactivity will be the one that produces a constant reaction rate/surface area ratio with conversion. The assumption of a constant ratio has been widely employed in modelling works [19].

In the present study, a PET sample was devolatilised in a vertical quartz reactor and the char obtained was partially $\mathrm{CO}_{2}$-gasified in order to achieve various degrees of conversion. The reactivity and kinetics of the chars were determined by using a thermogravimetric analyser. The objective was to study the variation of char reactivity with conversion and its relation to the properties of the char texture.

\section{Material and Methods}

\subsection{Preparation of char samples}

PET from post-consumer soft-drink bottles was cut into small pieces (squares of 1x1 cm approximately), and batches of this raw material $(40 \mathrm{~g})$ were pyrolysed at $725^{\circ} \mathrm{C}$ for $2 \mathrm{~h}$ under a $\mathrm{N}_{2}$ flow rate of $50 \mathrm{Nml} \mathrm{min-1}$ and a heating rate of $15^{\circ} \mathrm{C} \min ^{-1}$ in a $35 \mathrm{~mm}$ internal diameter vertical quartz reactor, heated by an electric furnace. The final products included $58 \%$ of gaseous compounds $\left(\mathrm{CO}, \mathrm{CO}_{2}\right.$ and hydrocarbons), $20 \%$ of terephthalic acid and $22 \%$ of char (denoted as PET0). The $\mathrm{CO}_{2}$ gasification experiments were carried out at a previously optimised temperature of $925^{\circ} \mathrm{C}[25]$; previously, PET0 sample was subjected to a treatment at $925{ }^{\circ} \mathrm{C}$ in a nitrogen atmosphere $\left(50 \mathrm{Nml} \mathrm{min}{ }^{-1}\right)$ for $1 \mathrm{~h}$, giving the initial char sample for $\mathrm{CO}_{2}$ gasification tests, which was denoted as PC00. Sample PC00 was then partially gasified in the same experimental device under a 


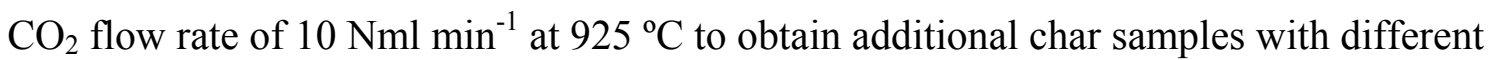
conversion degrees $(12,35,58$ and $76 \%$ of burn-off), which were denoted as PC12, PC35, PC58 and PC76, respectively;. Therefore, the $\mathrm{CO}_{2}$ reactivity tests will be applied to the PC00, PC12, PC35, PC58 and PC76 samples.

\section{2. $\mathrm{CO}_{2}$ reactivity tests}

The reactivity tests were conducted in a thermobalance (Setaram TAG24) at atmospheric pressure. Approximately $5 \mathrm{mg}$ of char sample $(0.5-1.0 \mathrm{~mm})$ was placed in a crucible with a circular base ( $5 \mathrm{~mm}$ diameter and $2 \mathrm{~mm}$ height). A thermocouple was located close to the platinum basket to monitor temperature and to close the oven control loop. The following experimental procedure was applied to the PC00, PC12, PC35, PC58 and PC76 samples in the thermobalance. Firstly, the sample was heated up to $1125^{\circ} \mathrm{C}\left(100{ }^{\circ} \mathrm{C} \min ^{-1}\right)$ under $\mathrm{N}_{2}$ flow $\left(50 \mathrm{Nml} \mathrm{min}^{-1}\right)$. Secondly, sample reactivity was evaluated by means of isothermal thermogravimetric $\mathrm{CO}_{2}\left(50 \mathrm{Nml} \mathrm{min} \mathrm{m}^{-1}\right)$ gasification until completion at five temperatures: 925, 975, 1025, 1075 and $1125^{\circ} \mathrm{C}$. Then, the char conversion, $X$, and reaction rate, $\mathrm{d} X / \mathrm{d} t$, were calculated."

The random pore model, RPM, [14] was used in order to evaluate the reactive behaviour of the chars. The reaction rate, $\mathrm{d} X / \mathrm{d} t$, is expressed as:

$\mathrm{d} X / \mathrm{d} t=k(1-X)[1-\psi \ln (1-X)]^{1 / 2}$

where $X$ is the char conversion on a dry ash-free basis, $k$ is the apparent gasification reaction rate and $\psi$ is a parameter related to the pore structure of the unreacted sample $(X=0)$. The apparent reaction rate, $k$, can be expressed using the Arrhenius equation, which is written as:

$k=k_{0} \mathrm{e}^{-E / R T}$ 
where $k_{0}$ and $E$ are the pre-exponential factor and activation energy, respectively. The parameter $\psi$ can be calculated by the following equation:

$\psi=4 \pi L_{0}\left(1-\varepsilon_{0}\right) / S_{0}^{2}$

where $S_{0}, L_{0}$ and $\varepsilon_{0}$ represent the pore surface area, pore length and solid porosity, respectively. Eq. (1) was linearised in order to calculate the values of $k$ and $\psi$ from the experimental data obtained in the isothermal thermogravimetric runs, giving:

$(2 / \psi)\left[(1-\psi \ln (1-X))^{1 / 2}-1\right]=k t$

The random pore model provides the following conversion-time relationship [26]:

$X=1-\exp [-k t(1+k t \psi / 4)]$

Equation (5) was used to calculate $X_{\text {calc, } i}$ introducing the previously estimated $k$ and $\psi$ values. The $X$ calculation was performed in order to calculate the quality of the fit and verify the capacity of the kinetic models to describe the char conversion by comparing the experimental and calculated $X$ values. The deviation (DEV) between the experimental and calculated curves was calculated using the following expression:

$\operatorname{DEV} X(\%)=100\left[\sum_{i=1, N}\left(X_{\exp , i}-X_{\text {calc }, i}\right)^{2} / \mathrm{N}\right]^{1 / 2} / \max X_{\exp }$

where $X_{\exp , i}$ and $X_{\mathrm{cal}, i}$ represent the calculated and experimental data of $X, N$ is the number of data points, and $\max X_{\exp }$ is the highest absolute value of the experimental curve.

\subsection{Textural characterisation}

Nitrogen adsorption isotherms at $-196^{\circ} \mathrm{C}$ were obtained using a Micromeritics ASAP $2010 \mathrm{M}$ instrument, while $\mathrm{CO}_{2}$ adsorption isotherms at $0{ }^{\circ} \mathrm{C}$ were obtained using a Micromeritics Gemini 2375 device. 
From the $\mathrm{N}_{2}$ adsorption isotherms, the apparent surface area of the samples was obtained by using the BET equation [27]. The Dubinin-Asthakov (DA) method [28] was also applied to both the $\mathrm{N}_{2}$ and $\mathrm{CO}_{2}$ adsorption isotherms in order to obtain the corresponding micropore volume, which then was used to calculate the micropore surface area of the chars [25].

\section{Results and discussion}

The elemental analysis and the surface areas of the char samples are shown in Table 1. When the BET equation was applied to the $\mathrm{N}_{2}$ adsorption isotherms, an increase in the apparent surface area (BET surface area) with conversion was found (Table 1). Furthermore, the physical structure of the solid reactant changed as the reaction proceeded. This evolution may have affected the kinetics of the reaction by altering the amount of surface area available for the reaction [29].

In order to follow and analyse the extent of adsorption by the micropores, it is useful to use $\mathrm{CO}_{2}$ at $0{ }^{\circ} \mathrm{C}$ together with $\mathrm{N}_{2}$ at $-196^{\circ} \mathrm{C}$, since by including the $\mathrm{CO}_{2}$ data it is possible to extend the range of analysis to the narrow microporosity [30]. The critical dimensions of both molecules are similar, but the higher temperature of the $\mathrm{CO}_{2}$ experiments avoids the kinetic restrictions that prevent the $\mathrm{N}_{2}$ probe from gaining access to the narrow micropores. Moreover, because of the much lower relative pressure range covered by the $\mathrm{CO}_{2}$ adsorption isotherms (up to $\mathrm{p} / \mathrm{p}_{0}<0.035$ ), the data correspond solely to the domain of the narrow microporosity [24].

In this study, the micropore surface area obtained from the $\mathrm{CO}_{2}$ adsorption isotherms was higher than that obtained from the $\mathrm{N}_{2}$ adsorption data up to $35 \%$ of conversion, whereas it was lower at higher values of conversion (Table 1). This indicates that the 
porosity present in the initial sample and at a low degree of burn-off (PC00 and PC12) consisted mostly of narrow micropores. Ballal and Zygourakis [31] stated that the pore volume obtained from $\mathrm{N}_{2}$ adsorption is lower than that obtained from $\mathrm{CO}_{2}$ adsorption because most of the smaller pores are not accessible to $\mathrm{N}_{2}$.

Furthermore, the surface area value obtained from the $\mathrm{N}_{2}$ adsorption isotherms, $\mathrm{N}_{2}$ (micro), remarkably increased from $0 \%$ to $35 \%$ of conversion but remained approximately constant at conversion values higher than $35 \%$, whereas that obtained from the $\mathrm{CO}_{2}$ adsorption isotherms reached a maximum at $35 \%$ of conversion but decreased as conversion increased to higher values (Table 1). Therefore, as the degree of conversion increased (PC35 to PC76), the surface area corresponding to narrow micropores decreased, whereas that associated with larger micropores did not appreciably change. When narrow micropores participate in the reaction, they initially become larger due to the fact that the reaction occurs on the pore surface, and this results in an increase in the surface area. However, as these pores get even bigger, they coalesce with neighbouring pores, with the result that the pore surface area decreases [32]. And at the same time, an increase in the surface area of higher micropore sizes occurs, leading to an increase in BET surface area (Table 1), again due to pore coalescence.

The linearised form of the RPM model, Eq. (4), was used to represent the experimental data obtained at all the temperatures studied (Fig. 1) in order to find the parameters $k$ and $\psi$ of best fit. The parameter $\psi$ was calculated assuming that its value is constant for each char sample at all the temperatures, since it is related to the pore structure. Table 2 shows the values of $k$ and $\psi$ that better fit the experimental data to the Eq. (4). The value of the $\psi$ parameter obtained for all the char samples hardly changed with the degree of 
conversion. Although the $\psi$ parameter is related to the textural properties of the solids, a relationship between the BET surface area (Table 1) and the $\psi$ values cannot be established. However, the $\psi$ values and the $\mathrm{CO}_{2}$ surface areas (Table 1) seem to present an inverse linear correlation.

The calculated conversion, $X_{\mathrm{calc}, i}$, of the chars during gasification was obtained with Eq. (5) by using the previously estimated $k$ and $\psi$ values (Table 2). In order to quantify the errors produced by the kinetic models in predicting the values of conversion, the experimental and calculated $X$ values were compared by calculating the deviation, DEV $X(\%)$, between the experimental and calculated curves using Eq. (6). Table 3 shows the results for this deviation for all the char samples and temperatures studied.

The Arrhenius plot (lnk vs. 1/T) was then employed (Fig. 2) to calculate the activation energy, $E$, and the pre-exponential factor, $k_{0}$, for each of the char samples at different degrees of conversion (Eq. 2). All the regression analysis carried out resulted statistically significant (confidence interval 95\%). The results corresponding to $1125{ }^{\circ} \mathrm{C}$ are not included in the regression because they were obtained under the diffusioncontrolled regime, as can be observed in the plot. The change from chemical to diffusion-controlled regime was detected from the change in slope on the Arrhenius plots.

The $E$ and $\ln k_{0}$ values were represented in relation to the conversion degree of each of the char samples studied (Fig. 3). As can be seen, there is no variation between these values with burn-off which seems to indicate that the reactivity parameters did not change with the conversion of the PET char.

However, the surface areas of the char samples were observed to change with conversion (Table 1). The reaction rate, $\mathrm{d} X / \mathrm{d} t$, of the initial char sample, PC00, was 
therefore normalized by each of the surface areas in order to be able to calculate the intrinsic reactivity. Only when the reaction rate was normalized by the narrow micropore surface areas calculated from the $\mathrm{CO}_{2}$ adsorption isotherms, was its value constant for all the degrees of conversion (Fig. 4), indicating that the variations in reaction rate are controlled by the narrow microporosity during the gasification reaction. Several authors have studied solid gasification kinetics related to development of the textural characteristics under different conditions. Su and Perlmutter [29] found that the coal char gasification kinetics is controlled by pore structural changes, although these authors worked with air instead of $\mathrm{CO}_{2}$. Arias et al. [33] studied the reaction kinetics by RPM model and found that the available surface area during coal combustion was best represented by $\mathrm{N}_{2}$ surface area. Salatino et al. [34] compared the gasification of coal by oxygen and carbon dioxide; they found that the micropores participate to a lesser extent to carbon gasification by $\mathrm{O}_{2}$ than by $\mathrm{CO}_{2}$. Feng and Bathia [20] found that the coal char reaction rate normalized by the total surface area for $\mathrm{CO}_{2}$ gasification was constant at conversions higher than $20 \%$. However, according to some authors, the micropores have not been completely filled. Hurt et al. [35] studied the gasification of chars from a sub-bituminous coal and found that the rate of $\mathrm{CO}_{2}$ gasification remained insensitive to large changes in total surface area during reaction, but these authors attributed this behaviour to an enhancement of active catalytic sites on the large pore surface areas. Ballal and Zygourakis [31] studied the evolution of pore surface area during gasification of coal chars and concluded that a large number of submicropores are probably not completely filled during the reaction with $\mathrm{O}_{2}$, whereas they are in the case of gasification with $\mathrm{CO}_{2}$. These authors also pointed out that $\mathrm{N}_{2}$ adsorption properties do 
not always give a good indication of the amount of microporosity accessible to $\mathrm{CO}_{2}$ gasification.

\section{Conclusions}

The kinetic parameters that define the reactivity of PET char in $\mathrm{CO}_{2}$ did not change during conversion, unlike the micropore surface areas. Determination of the intrinsic reactivity from the narrow micropore surface area gave satisfactory results. Thus, narrow micropore surface area appears to be a good parameter for describing the reactivity of PET char, since the ratio between the reaction rate and this type of surface area remained constant with conversion, indicating that the gasification process was governed by narrow microporosity.

\section{Acknowledgements}

M.V.Gil acknowledges funding from the CSIC JAE Program co-financed by the European Social Fund. Thanks are due to Dr. J.B. Parra for the samples used in this work.

\section{References}

[1] A.K. Gupta, D.G. Lilley, Energy recovery opportunities from wastes, J. Propul. Power 15 (1999) 175-180.

[2] EuPR. How to increase the mechanical recycling of post-consumer plastics. Strategy paper of the European plastics recyclers association (2010). (http://www.plasticsrecyclers.eu/; last accessed: June 14th 2010).

[3] J.B. Parra, C.O. Ania, A. Arenillas, F. Rubiera, J.M. Palacios, J.J. Pis, Textural development and hydrogen adsorption of carbon materials from PET waste, J. Alloy. Compd. 379 (2004) 280-289.

[4] I.I. Ahmed, A.K. Gupta, Hydrogen production from polystyrene pyrolysis and gasification: Characteristics and kinetics, Int. J. Hydrog. Energy 34 (2009) 62536264. 
[5] A.K. Gupta, D.G. Lilley, Incineration of plastics and other wastes for efficient power generation: a review, 41st Aerospace Sciences Meeting and Exhibit, Reno, Nevada, January 6-9, 2003.

[6] M. Pohořelý, M. Vosecký, P. Hejdová, M. Punčochář, S. Skoblja, M. Staf, J. Vošta, B. Koutský, K. Svoboda, Gasification of coal and PET in fluidized bed reactor, Fuel 85 (2006) 2458-2468.

[7] F. Pinto, C. Franco, R.N. André, M. Miranda, I. Gulyurtlu, I. Cabrita, Cogasification study of biomass mixed with plastic wastes, Fuel 81 (2002) 291-297.

[8] S.M. Al-Salem, P. Lettieri, J. Baeyens, The valorization of plastic solid waste (PWS) by primary to quaternary routes: From re-use to energy and chemicals, Prog. Energy Combust. Sci. 36 (2010) 103-129.

[9] J. Fermoso, B. Arias, C. Pevida, M.G. Plaza, F. Rubiera, J.J. Pis, Kinetic models comparison for steam gasification of different nature fuel chars, J. Therm. Anal. Calorim. 91 (2008) 779-786.

[10] A. Arenillas, F. Rubiera, J.J. Pis, J.M. Jones, A. Williams, The effect of the textural properties of bituminous coal chars on NO emissions, Fuel 78 (1999) 1779-1785.

[11] A. Arenillas, F. Rubiera, B. Arias, J.J. Pis, J.M. Faúndez, A.L. Gordon, X.A. García, A TG/DTA study on the effect of coal blending on ignition behaviour, J. Therm. Anal. Calorim. 76 (2004) 603-614.

[12] F. Rubiera, A. Arenillas, C. Pevida, R. García, J.J. Pis, K.M. Steel, J.W. Patrick, Coal structure and reactivity changes induced by chemical demineralisation, Fuel Process. Technol. 79 (2002) 273-279.

[13] J.J. Pis, G. de la Puente, E. Fuente, A. Morán, F. Rubiera, A study of the selfheating of fresh and oxidized coals by differential thermal analysis, Thermochim. Acta 279 (1996) 93-101.

[14] S.K. Bhatia, D.D. Perlmutter, A random pore model for fluid-solid reactions: I. Isothermal, kinetic control, AIChE J. 26 (1980) 379-386.

[15] S. Kajitani, S. Hara, H. Matsuda, Gasification rate analysis of coal char with a pressurized drop tube furnace, Fuel 81 (2002) 539-546.

[16] J.H. Zou, Z.J. Zhou, F.C. Wang, W. Zhang, Z.H. Dai, H.F. Liu, Z.H. Yu, Modeling reaction kinetics of petroleum coke gasification with $\mathrm{CO}_{2}$, Chem. Eng. Process. 46 (2007) 630-636.

[17] K. Matsumoto, K. Takeno, T. Ichinose, T. Ogi, M. Nakanishi, Gasification reaction kinetics on biomass char obtained as a by-product of gasification in an entrainedflow gasifier with steam and oxygen at $900-1000{ }^{\circ} \mathrm{C}$, Fuel 88 (2009) 519-527.

[18] Y. Okumura, T. Hanaoka, K. Sakanishi, Effect of pyrolysis conditions on gasification reactivity of woody biomass-derived char, Proc. Combust. Inst. 32 (2009) 2013-2020.

[19] R. Sahu, Y.A. Levendis, R.C. Flagan, G.R. Gavalas, Physical properties and oxidation rates of chars from three bituminous coals, Fuel 67 (1988) 275-283.

[20] B. Feng, S.K. Bhatia, Variation of the pore structure of coal chars during gasification, Carbon 41 (2003) 507-523.

[21] S.J. Gregg, K.S.W. Sing, Adsorption, surface area and porosity, Academic Press, New York, 1982.

[22] O.P. Mahajan, P.L. Walker Jr., Analytical methods for coal and coal products, Academic Press, New York, 1978.

[23] P.A. Webb, C. Orr, Analytical methods in fine particle technology, Micromeritics Instruments, 1997. 
[24] D. Lozano-Castelló, D. Cazorla-Amorós, A. Linares-Solano, Usefulness of $\mathrm{CO}_{2}$ adsorption at $273 \mathrm{~K}$ for the characterization of porous carbons, Carbon 42 (2004) 1233-1242.

[25] J.B. Parra, C.O. Ania, A. Arenillas, F. Rubiera, J.J. Pis, High value carbon materials from PET recycling, Appl. Surf. Sci. 238 (2004) 304-308.

[26] K.N. Tran, S.K. Bathia, A. Tomsett, Air reactivity of petroleum cokes: role of inaccessible porosity, Ind. Eng. Chem. Res. 46 (2007) 3265-3274.

[27] J.B. Parra, J.C. de Sousa, R.C. Bansal, J.J. Pis, J.A. Pajares, Characterization of activated carbons by BET equation. An alternative approach, Adsorpt. Sci. Technol. 12 (1995) 51-66.

[28] M.M. Dubinin, V.A. Astakhov, Description of adsorption equilibria of vapors on zeolites over wide ranges of temperature and pressure, Advances in Chemistry Series 102 (1971) 69-85.

[29] J.L. Su, D.D. Perlmutter, Effect of pore structure on char oxidation kinetics, AIChE J. 31 (1985) 973-981.

[30] C.O. Ania, J.B. Parra, F. Rubiera, A. Arenillas, J.J. Pis, A comparison of characterization methods based on $\mathrm{N}_{2}$ and $\mathrm{CO}_{2}$ adsorption for the assessment of the pore size distribution of carbons, Studies in Surface Science and Catalysis 160 (2007) 319-326.

[31] G. Ballal, K. Zygourakis, Evolution of pore surface area during noncatalytic gassolid reactions. 2. Experimental Results and Model Validation, Ind. Eng. Chem. Res. 26 (1987) 1787-1796.

[32] G. Ballal, K. Zygourakis, Evolution of pore surface area during noncatalytic gassolid reactions. 1. Model Development, Ind. Eng. Chem. Res. 26 (1987) 911-921.

[33] B. Arias, C. Pevida, F. Rubiera, J.J. Pis, Changes in coal char reactivity and texture during combustion in an entrained flow reactor, J. Therm. Anal. Calorim. 90 (2007) 859-863.

[34] P. Salatino, O. Senneca, S. Masi, Gasification of a coal char by oxygen and carbon dioxide, Carbon 36 (1998) 443-452.

[35] R.H. Hurt, A.F. Sarofim, J.P. Longwell, The role of microporous surface area in the gasification of chars from a sub-bituminous coal, Fuel 70 (1991) 1079-1082. 


\section{Figure captions}

Fig. 1. RPM linearised model for the PET char samples at different conversion degrees (a: PC00; b: PC12; c: PC35; d: PC58; and e: PC76) during $\mathrm{CO}_{2}$ gasification at different temperatures.

Fig. 2. Arrhenius plot for the RPM model of the PET char samples at different conversion degrees (PC00, $\mathrm{PC} 12, \mathrm{PC} 35, \mathrm{PC} 58$; and $\mathrm{PC} 76)$ during $\mathrm{CO}_{2}$ gasification.

Fig. 3. Variation of the RPM model pre-exponential factor, $\ln k_{0}$, and the activation energy, $E$, with conversion during the $\mathrm{CO}_{2}$ gasification of PET char.

Fig. 4. Variation of the normalized reaction rate of char sample PC00 for the different micropore surface areas with conversion during the $\mathrm{CO}_{2}$ gasification of PET char (a: $925^{\circ} \mathrm{C}$; b: $975^{\circ} \mathrm{C}$; c: $1025^{\circ} \mathrm{C}$; and d: $\left.1075^{\circ} \mathrm{C}\right)$. 
Table 1

Elemental analysis and surface areas of char samples

\begin{tabular}{|c|c|c|c|c|c|c|}
\hline \multirow[t]{2}{*}{ Char sample } & \multicolumn{3}{|c|}{ Elemental analysis (wt $\%$, dry basis) } & \multicolumn{3}{|c|}{ Surface areas $\left(\mathrm{m}^{2} / \mathrm{g}\right)$} \\
\hline & $\mathrm{C}$ & $\mathrm{H}$ & $\mathrm{O}$ & $\mathrm{BET}^{\mathrm{a}}$ & $\mathrm{N}_{2}(\text { micro })^{\mathrm{b}}$ & $\mathrm{CO}_{2}$ (narrow micro) ${ }^{\mathrm{c}}$ \\
\hline$\overline{\mathrm{PC} 00}$ & 98.2 & 0.5 & 0.9 & 340 & 490 & 746 \\
\hline $\mathrm{PC} 12$ & 98.8 & 0.3 & 0.6 & 668 & 629 & 882 \\
\hline PC35 & 98.9 & 0.3 & 0.6 & 1405 & 909 & 969 \\
\hline PC58 & 98.7 & 0.2 & 0.6 & 1920 & 930 & 748 \\
\hline PC76 & 99.0 & 0.2 & 05 & 2468 & 870 & 480 \\
\hline
\end{tabular}

${ }^{a}$ Determined by the BET method applied to the $\mathrm{N}_{2}$ adsorption isotherms at $-196{ }^{\circ} \mathrm{C}$.

${ }^{b}$ Determined by the DA method applied to the $\mathrm{N}_{2}$ adsorption isotherms at $-196{ }^{\circ} \mathrm{C}$.

${ }^{\mathrm{c}}$ Determined by the DA method applied to the $\mathrm{CO}_{2}$ adsorption isotherms at $0{ }^{\circ} \mathrm{C}$. 
Table 2

Values of the parameters $k$ and $\psi$ that better fit the experimental data from $\mathrm{CO}_{2}$ gasification at different temperatures to the RPM Char sample $\quad \psi \quad \underline{k \pm \text { standard error }\left(\times 10^{-5} \mathrm{~s}^{-1}\right)}$

\begin{tabular}{|c|c|c|c|c|c|c|}
\hline \multirow[t]{2}{*}{ Char sample } & \multirow[t]{2}{*}{$\psi$} & \multicolumn{5}{|c|}{$k \pm$ standard error $\left(\times 10^{-5} \mathrm{~s}^{-1}\right)$} \\
\hline & & $925^{\circ} \mathrm{C}$ & $975^{\circ} \mathrm{C}$ & $1025^{\circ} \mathrm{C}$ & $1075^{\circ} \mathrm{C}$ & $1125^{\circ} \mathrm{C}$ \\
\hline $\mathrm{PC} 00$ & $3.0 \pm 0.01$ & $8.9 \pm 0.02$ & $21.4 \pm 0.05$ & $66.6 \pm 0.34$ & $141.3 \pm 0.71$ & $254.2 \pm 0.92$ \\
\hline $\mathrm{PC} 12$ & $2.8 \pm 0.01$ & $9.1 \pm 0.01$ & $25.5 \pm 0.07$ & $50.7 \pm 0.21$ & $150.8 \pm 0.96$ & $199.4 \pm 0.28$ \\
\hline PC35 & $2.6 \pm 0.01$ & $9.8 \pm 0.02$ & $29.5 \pm 0.04$ & $64.9 \pm 0.12$ & $148.8 \pm 0.76$ & $276.7 \pm 0.34$ \\
\hline PC58 & $3.3 \pm 0.01$ & $9.4 \pm 0.01$ & $26.2 \pm 0.03$ & $65.1 \pm 0.13$ & $168.9 \pm 0.59$ & $288.0 \pm 1.10$ \\
\hline PC76 & $3.9 \pm 0.01$ & $9.7 \pm 0.01$ & $25.4 \pm 0.05$ & $59.4 \pm 0.14$ & $140.7 \pm 0.71$ & $254.2 \pm 1.19$ \\
\hline
\end{tabular}


Table 3

Deviation (\%) between the experimental and calculated conversion $(X)$ data for RPM during $\mathrm{CO}_{2}$ gasification at different temperatures

\begin{tabular}{llllll}
\hline Char & \multicolumn{2}{l}{ DEV $X(\%)$} & & & \\
\cline { 2 - 6 } sample & $925^{\circ} \mathrm{C}$ & $975^{\circ} \mathrm{C}$ & $1025^{\circ} \mathrm{C}$ & $1075^{\circ} \mathrm{C}$ & $1125^{\circ} \mathrm{C}$ \\
\hline PC00 & 1.8 & 1.4 & 2.0 & 2.2 & 0.7 \\
PC12 & 1.3 & 1.3 & 1.7 & 2.0 & 0.4 \\
PC35 & 1.2 & 0.7 & 0.6 & 1.7 & 0.4 \\
PC58 & 0.5 & 0.6 & 0.8 & 1.1 & 0.6 \\
PC76 & 0.8 & 0.8 & 0.9 & 1.7 & 1.5 \\
\hline
\end{tabular}



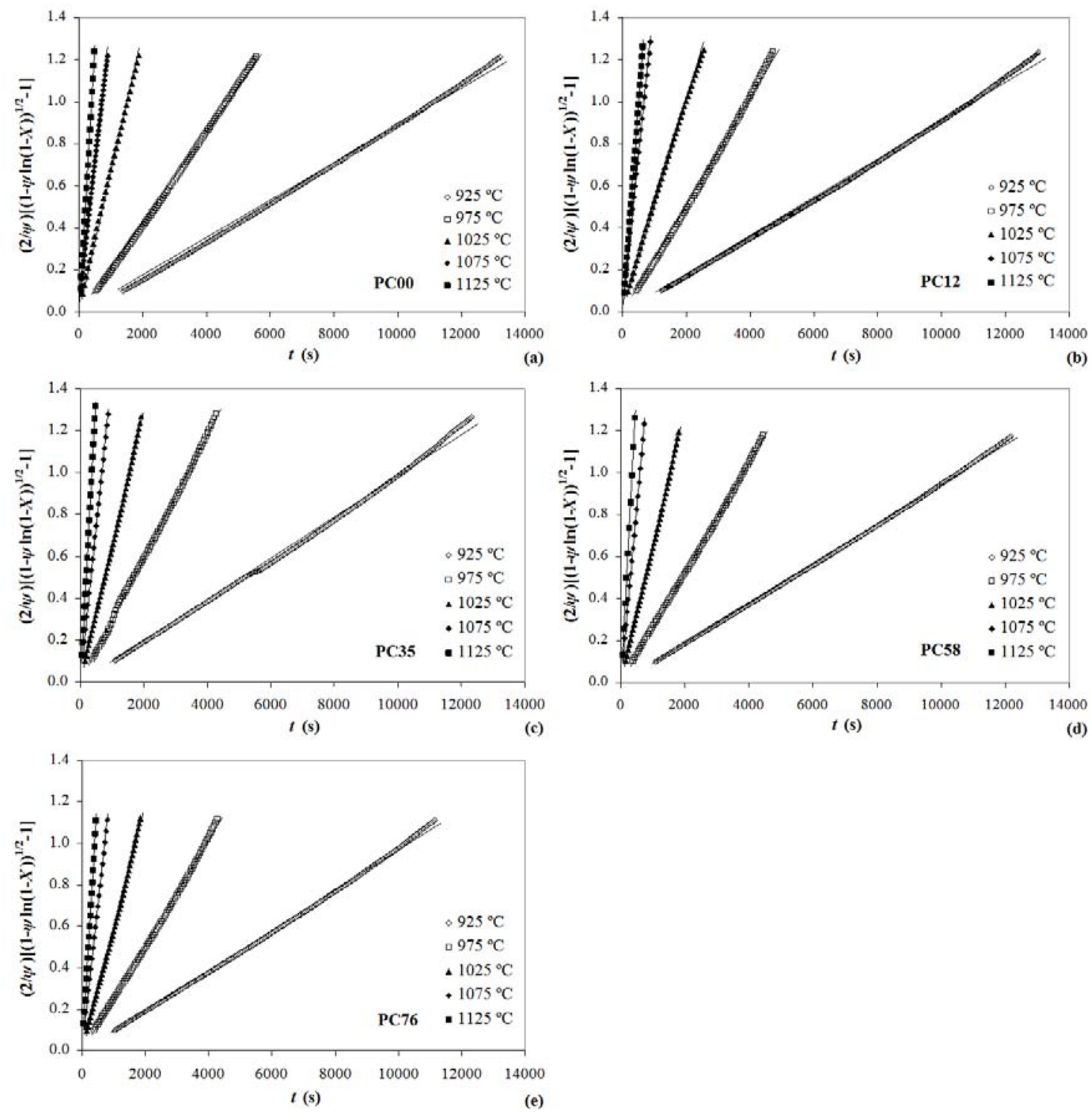

Fig. 1. RPM linearised model for the PET char samples at different conversion degrees (a: PC00; b: PC12; c: PC35; d: PC58; and e: $\mathrm{PC} 76$ ) during $\mathrm{CO}_{2}$ gasification at different temperatures. 


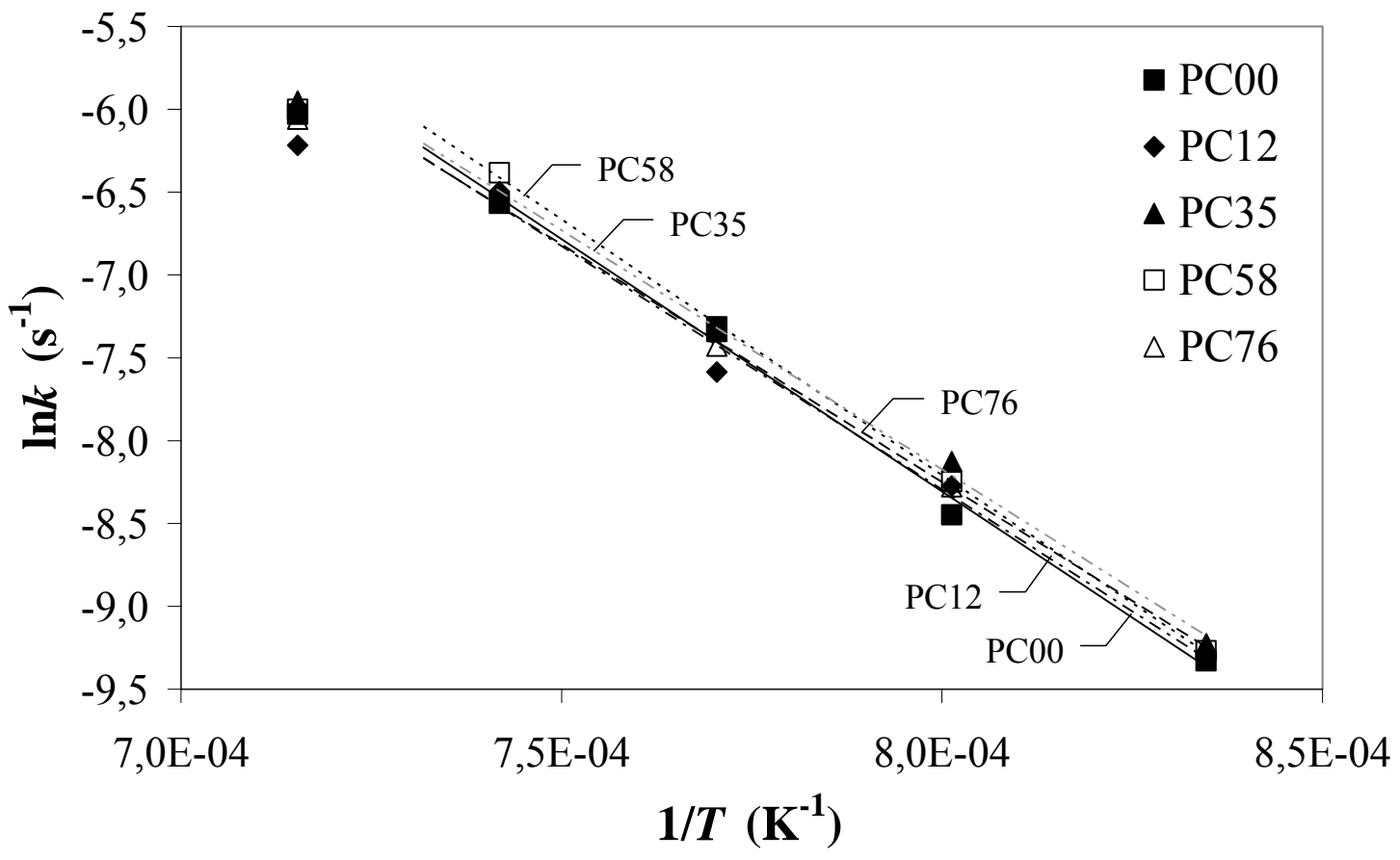

Fig. 2. Arrhenius plot for the RPM model of the PET char samples at different conversion degrees (PC00, $\mathrm{PC} 12, \mathrm{PC} 35, \mathrm{PC} 58$ and $\mathrm{PC} 76)$ during $\mathrm{CO}_{2}$ gasification. 


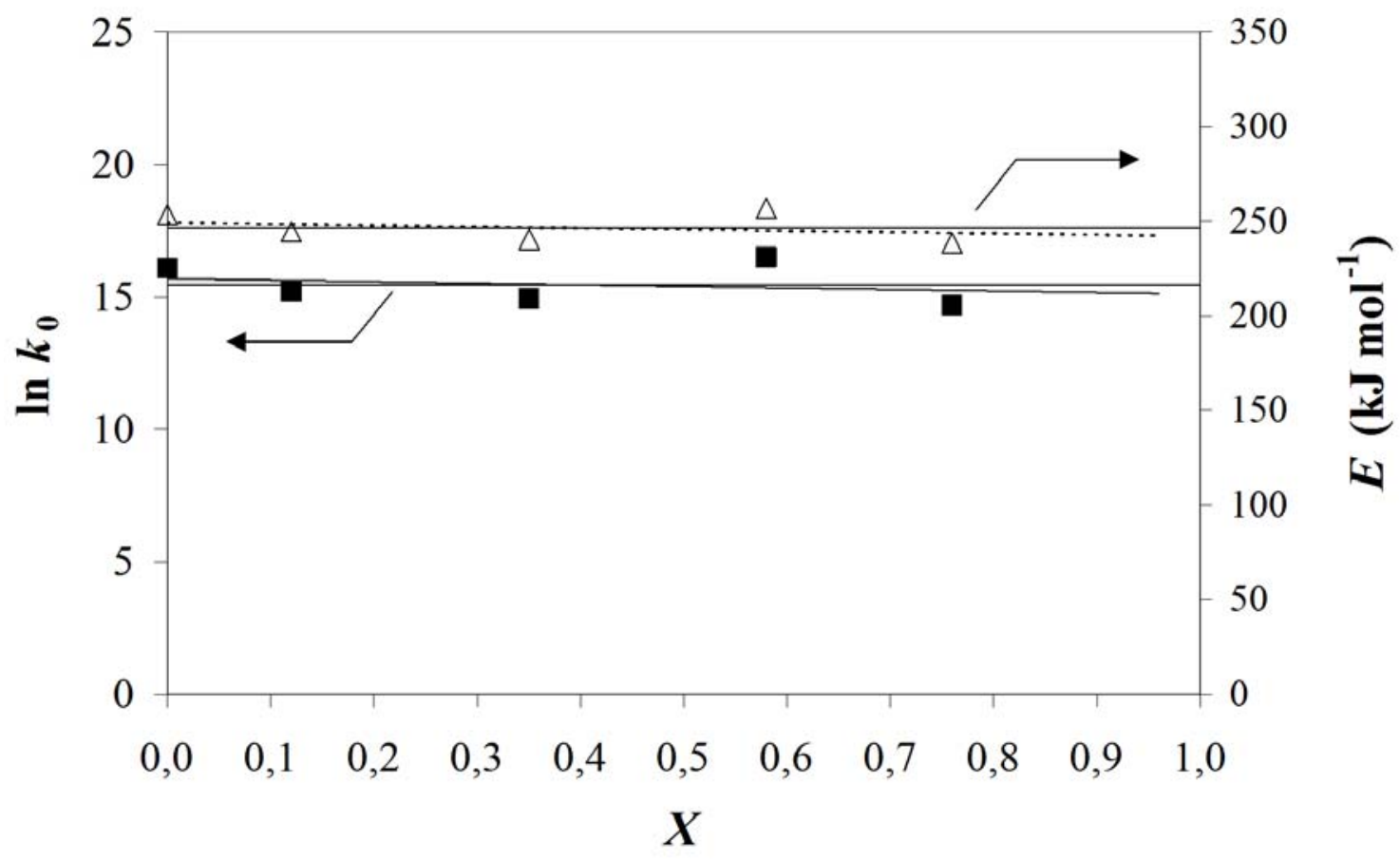

Fig. 3. Variation of the RPM model pre-exponential factor, $\ln k_{0}$, and the activation energy, $E$, with conversion during the $\mathrm{CO}_{2}$ gasification of PET char. 

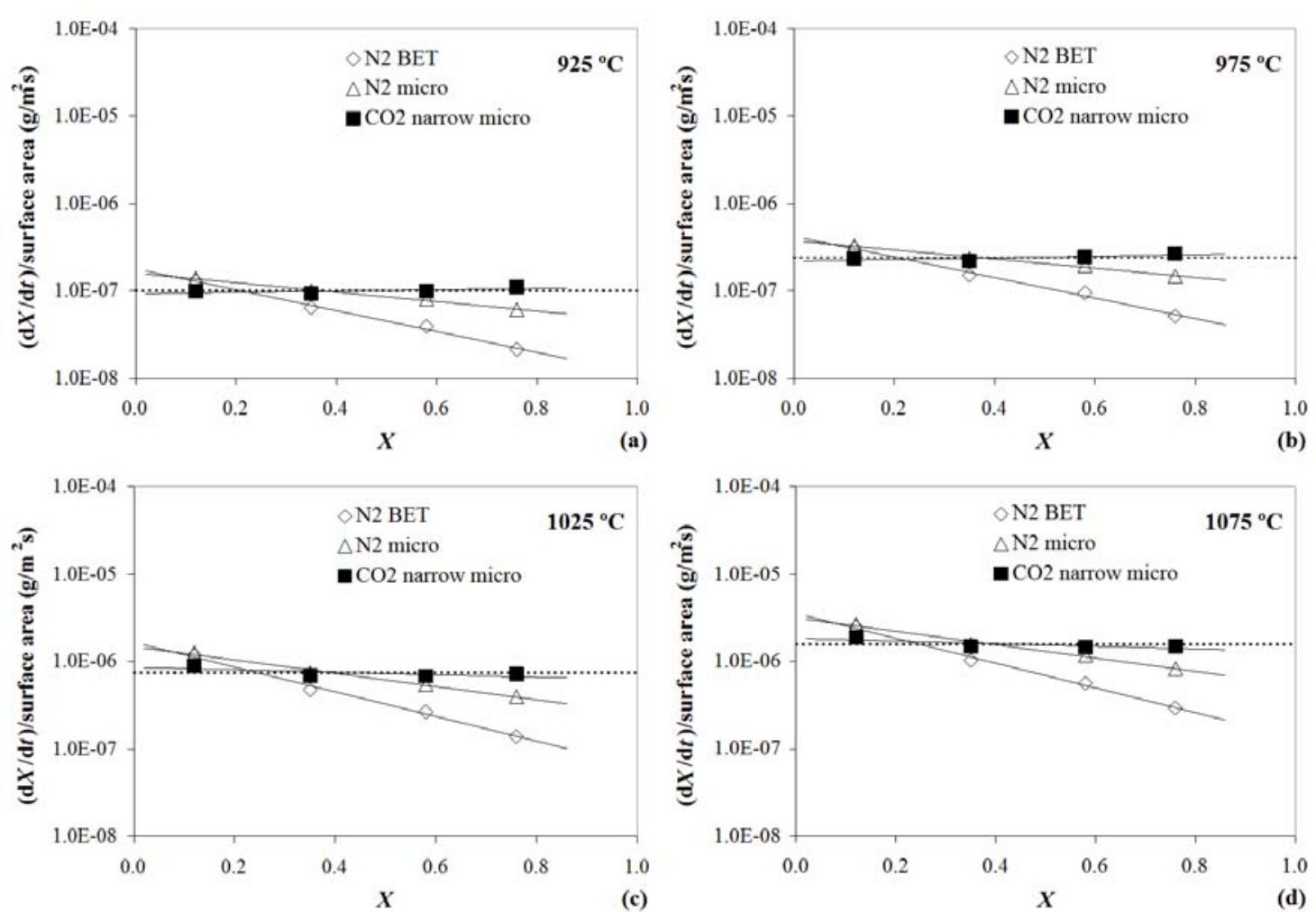

Fig. 4. Variation of the normalized reaction rate of char sample PC00 for the different micropore surface areas with conversion during the $\mathrm{CO}_{2}$ gasification of PET char (a: $925^{\circ} \mathrm{C}$; b: $975^{\circ} \mathrm{C}$; c: $1025^{\circ} \mathrm{C}$; and d: $\left.1075^{\circ} \mathrm{C}\right)$. 